


\title{
María Zambrano y la quimera
}

\section{María Zambrano and the Chimera}

\author{
Pablo Muñoz Covarrubias \\ Universidad Autónoma Metropolitana-Iztapalapa, México \\ juanpablomunozcovarrubias@gmail.com
}

Resumen: A lo largo de su carrera como filósofa, escritora y pensadora, María Zambrano concibió la literatura como un espacio privilegiado de investigación. La autora estudió las posibilidades de la razón poética en diversos géneros, tales como la poesía y la novela. El propósito de las siguientes páginas es investigar la manera en que leyó y recreó las obras literarias, en especial, aquellas de la autoría de Miguel de Cervantes y Benito Pérez Galdós. Su crítica literaria se vinculó con el simbolismo de la metáfora. Uno de los símbolos más recurrentes en sus textos es la quimera. La quimera se convierte en una indispensable y ambigua imagen en sus análisis de Don Quijote y Misericordia.

Palabras clave: María Zambrano, crítica literaria, razón poética, Cervantes, Pérez Galdós.

Abstract: During her career as a philosopher, writer and thinker, María Zambrano once and again portrayed literature as a special space for her research. In that sense, she investigated the principal traits belonging to the poetic reason in several genres such as poetry and fiction. The purpose of the following pages is to investigate the way in which she read 
and recreated literary works chiefly by Miguel de Cervantes and Benito Pérez Galdós. Her literary criticism is anchored to metaphoric symbolism. One of her most recurrent symbols is the chimera. The chimera becomes an indispensable and ambiguous image in her analysis of Don Quixote and Misericordia.

Keywords: María Zambrano, Literary Criticism, Poetic reason, Cervantes, Pérez Galdós.

Recibido: 2I enero de 2020

Aceptado: Io de diciembre de 2020 https://dx.doi.org/ I0.15 I74/rv.vi3i28.523

\section{María Zambrano y la quimera}

La primera noticia de la Quimera está en el libro VI de la Ilíada. Ahi está escrito que era de linaje divino y que por delante era un león, por el medio una cabra y por el fin una serpiente; echaba fuego por la boca y la mató el hermoso Belerofonte, hijo de Glauco, según lo habian presagiado los dioses.

Jorge Luis Borges y MARgarita Guerrero, MANUAL DE ZOOLOGÍA FANTÁSTICA La metáfora se enriquece y despliega y llega a convertirse en mito.

María Zambrano, "Las dos metáforas DEL CONOCIMIENTO" 


\section{Introducción}

U na porción significativa de la obra de la filósofa española María Zambrano (1904-1991) refleja su permanente interés por la literatura y por lo literario. En los juveniles artículos que se reunieron en Los intelectuales en el drama de España-preparados y publicados primeramente durante los ańos de la Guerra Civil, es decir, entre 1936 y 1939-, encontraremos importantes ensayos en que la filósofa investiga textos poéticos y novelísticos, los cuales ya recibieron, en los análisis correspondientes, la iluminación de la "razón poética". En "La reforma del entendimiento español" (1937), la escritora observó interesantemente que "supone la novela una riqueza humana mucho mayor que la Filosofía, porque supone que algo está ahí, que algo persiste en el fracaso; el novelista no construye ni ańade nada a sus personajes, no reforma la vida, mientras el filósofo la reforma, creando sobre la vida espontánea una vida según pensamientos, una vida creada, sistematizada. La novela acepta al hombre tal y como es en su fracaso, mientras la Filosofía avanza sola, sin supuestos" (2015: 213). Si bien Zambrano puso todo su ingenio en el estudio de obras literarias, y las valoró más que nadie, como nos lo revela la cita, no por ello deja de resultar indispensable preguntarnos si lo que hallamos en las páginas de sus ensayos se puede considerar estrictamente como crítica literaria. Ha de depender nuestra respuesta, por supuesto, de lo que consideremos como crítica y del concepto que propongamos para el estudio de la literatura. En este contexto, quizás valdría la pena citar unas pocas palabras de un libro clásico que modeló grandemente el trabajo académico durante el siglo anterior, y que nos servirá para empezar a detectar la originalidad en el trabajo desarrollado, por su parte, por María Zambrano: "El estudioso ha de traducir a términos intelectuales su experiencia de la literatura, incorporarla en un esquema coherente, que ha de ser 
racional si ha de ser conocimiento" (17). Con estas palabras, los profesores René Wellek y Austin Warren establecían la necesidad de lo esquemático y de lo racional en la construcción del saber literario, aspectos que fijan una distancia insalvable con la acostumbrada manera de proceder de nuestra autora. Sin embargo, hay un elemento en que creemos reconocer una coincidencia: la construcción del conocimiento, o la búsqueda de ese conocimiento, en el caso de la filósofa, por medio de la reflexión escritural activa en torno a asuntos que su prosa simultáneamente, según lo creemos, oscurece y alumbra, por ejemplo, en las obras literarias de Miguel de Cervantes y Benito Pérez Galdós, autores que para ella fueron siempre materia de estudio y de profundos comentarios. Recordemos que para Zambrano, como lo dejó apuntado en Los sueños y el tiempo, "todo conocimiento deja lugar a dudas, suscita dudas, interrogaciones; hace sentir, aun apareciendo como enteramente válido, su insuficiencia” (2014: 912). Leer e investigar su obra dará constancia de ello: de todas las dudas y de las interrogaciones que su escritura va despertando. ${ }^{1}$

Podríamos reconocer de inmediato que el método de la filósofa dista de ser, por supuesto, el filológico o el historicista. No encontraremos en las páginas de Zambrano -nada tan opuesto a su personalidad- una pretendida cientificidad al leer y al comentar, por ejemplo, la obra poética de San Juan de la Cruz o el significado de la locura y la cordura de Don Quijote de la Mancha. En esto parece acercarse a uno de sus principales maestros: Miguel

${ }^{1}$ José Luis Abellán explicó de este modo el mecanismo por medio del cual la filósofa propuso llegar al conocimiento: "el conocimiento poético, que está hecho de no renunciar a nada, en un afán de abarcarlo todo en su plenitud, sin reduccionismos de ninguna clase, es un conocimiento que se cumple por la vía del enamoramiento del mundo. Este conocimiento sólo se logra por medio de una intuición poética, o mejor, de lo que la misma María Zambrano ha llamado razón poética, único método posible de acceso a ese saber del alma” (263). 
de Unamuno. En ambos casos, los escritores rebasan las intenciones primarias que vehiculan la crítica literaria como ejercicio de comprensión y explicación directa del texto. Y por tanto de cualquier intencionalidad teórica, objetiva o racionalista. En realidad, el texto funciona para ellos como una suerte de espejo en que encuentran su propia imagen; $y$, por tanto, los temas que más les interesaban desde una perspectiva personalísima, incluso antes de comenzar la exégesis. La lectura que María Zambrano propone de la novela Misericordia (1897) de Pérez Galdós es de una originalidad indisputable. Lo es entre otros motivos por el uso del lenguaje críptico (y acaso poético) con que comenta la novela y por la conceptualización que la filósofa arma y desarma a lo largo de sus apuntes del texto galdosiano: allí ella busca lo que sabía que iba a encontrar. ${ }^{2}$ Lo mismo podría decirse de su ensayos acerca del Quijote: son artículos, como se verá más adelante en este trabajo, que se sumergen en las profundidades de la novela cervantina por medio de un vocabulario y un conjunto de términos que terminan por devolvernos una imagen bastante peculiar e incluso enigmática del libro. ${ }^{3}$ Para Zambrano -vale recordarlo-, no hay una fron-

${ }^{2}$ Para María Luisa Maillard, el encuentro temprano con Nina, protagonista de Misericordia, abrirá dos senderos para Zambrano: "1. La búsqueda de figuras simbólicas capaces de alumbrar sobre la verdadera naturaleza humana [...] 2. La búsqueda de un saber inesperado, capaz de procurar la revelación del hombre y que ella denominará 'razón poética', un saber que tenga en cuenta el sentir, íntimamente relacionado con los sueños y el tiempo y que encontrará en los símbolos su lugar natural de manifestación" (512).

${ }^{3}$ Ana Bundgård ha observado que "los ensayos sobre el Quijote publicados en España, sueño y verdad giran en torno al concepto de ambigüedad aplicado a Cervantes y a don Quijote como ente de ficción. Vistos en conjunto, esos ensayos contienen una teoría de la realidad, de 'la verdad de la vida' y de 'la vida de verdad'. Es decir, se trata de una ontología y una metafísica fundamentadas en la religación del ser humano con lo sagrado, entendido ello como arcano irreductible que apunta a un sentir originario de la persona" (2018:13). 
tera clara que diferencie los textos en que se dedica al examen de las obras literarias o al estudio de asuntos netamente filosóficos: esto desde el punto de vista discursivo. Sin embargo, como bien lo ha advertido la investigadora Goretti Ramírez, "frente a los filósofos que usan la literatura como ilustración a sus ideas, María Zambrano extrae su pensamiento de los textos literarios mismos; o los usa como pretexto para desarrollar sus propias ideas que más le preocupan" (53). De este modo, las obras literarias se convierten en estímulos o puntos de arranque para la indagación de asuntos que, de hecho, la pensadora habrá explorado en otros libros suyos dedicados al estudio de temas que terminan por reaparecer en los apuntes de orden crítico, creando así un universo y una red en que se van interconectando los asuntos, las imágenes, las ideas, las recurrencias, los recursos, las metáforas. En particular, pienso en el tema de los sueños y de la divinidad y de lo trágico y lo mítico y lo histórico. ${ }^{4}$

En Notas de un método, María Zambrano escribió que "la experiencia preside a todo método" (18). En el caso de la crítica literaria, dicha experiencia tendría que ser, desde luego, la atenta lectura de las obras que posteriormente serán comentadas y, en el caso de nuestra filósofa, reinventadas o reconstruidas. La intención de las siguientes páginas es precisamente averiguar cómo ocurre esto en los estudios más importantes que Zambrano dedicó al examen de

${ }^{4}$ En un artículo en que estudia el carácter teórico de los ensayos de Zambrano, escribió Roberta Johnson: "Perhaps her approach to or use of literature could be called a method or a mode, although vision is perhaps best. In these books she develops lucid and original thinking that centers on a literary text. One comes away from reading them with a new and fresh look at the work she has discussed; but more than that, one is infused with a philosophical concept that goes beyond the text. The text has been the focus of her essay, but only aspects of the work the author had probably not considered" (216). 
la obra de Galdós y de Miguel de Cervantes, escritores a los que, como ya quedó anotado, recurrentemente volvió durante toda su vida. Se trata sin duda de una tarea descomunal. Aquí nos abocaremos únicamente al estudio de un solo recurso con que la filósofa traza sus impresiones y sugerencias. Para ello, atenderemos un asunto que ha sido previamente estudiado por los especialistas: el uso de lo metafórico en su pensamiento. Hemos de coincidir con Gabriel Astey quien observó que "[...] los tropos zambranianos cumplen dos funciones: ser concreciones equívocas de 'conceptos' no cabalmente conceptuables, y al mismo tiempo motores de la producción de sentido en el discurso en que comparecen" (152). Pero más que lo metafórico, atenderemos una alegoría específica que Zambrano utiliza de forma frecuente, a lo largo de un par de décadas, con el propósito de representar casi plásticamente algunas de sus más complejas intuiciones literarias: la quimera. Para Zambrano, la simbología proveniente del mundo animal no fue cosa desconocida. Llegó a observar, también en sus Notas de un método, que "son los animales símbolos, reales o imaginarios, que acompañan como emblema a los dioses y a los hombres dotados de superior fuerza y destino, signos de una cualidad divina en el hombre. Animales que se posaron sobre un ser humano en simbiosis, de lo que el centauro y la sirena ofrecen paradigma” (33). Si bien en esta cita no incluyó la quimera entre los animales simbióticos o fantásticos, es una figura imaginaria que le sirve para describir fenómenos diversos, pero que siempre tiene en su prosa, como ya lo observaremos, la capacidad de reunir lo que de otro modo no podríamos considerar como plenamente unificado o reunido. La quimera es un animal imposible y por ello, paradójicamente, puede ilustrar mejor que cualquier otro símbolo la sutileza de los conceptos expuestos por la escritora. 


\section{La quimera y Don Quijote}

En "La ambigüedad de Cervantes" (2014: 685-695), artículo publicado originalmente en Sur en 1947, no hemos de encontrar todavía la quimera. Sin embargo, en este ensayo aparecen algunas ideas que se entremezclan con planteamientos vertidos en otros textos de la filósofa y que pueden servirnos para empezar a investigar su concepción de la novela, de ese privilegiado espacio de revelación e iluminación, espacio sacramental, que era para ella, sin duda, el texto literario y poético. En este artículo, la autora expuso sus ideas en torno al autor Miguel de Cervantes, también acerca del personaje principal de la novela; sin embargo, no nos propone un análisis que profundice en alguno de estos tres elementos concretos; lo que nos ofrece es, en cambio, un viaje reflexivo -más amplio y todavía más complejo- en que investiga la naturaleza del género novelístico, el lugar que ocuparía en el devenir del hombre como categoría, digamos, formativa o formadora de su propia humanidad. Lo primero que hay que decir es que Zambrano halla en el Quijote algo más que un libro: será la cifra entera del español -"es casi un signo totémico" (2015:685) - y, de forma más general, ha de serlo del hombre, pues la obra ejemplifica el permanente conflicto que vivimos y en que todos, a su vez, nos recreamos al leer las aventuras del caballero andante: es también sin duda nuestro símbolo. Lo que asombra a Zambrano es que esa cifra máxima se haya manifestado no en un texto épico o trágico, sino en el moderno género de la novela, el cual pareciera contraponerse, también, al mito, a "esos grandes cuentos que son los mitos en que los dioses andan entremezclados con los hombres" (2014: 688). Zambrano ve todavía en la figura de Don Quijote, a pesar de los deslindes genéricos que propone en este ensayo, el "más claro mito, lo más cercano a la imagen sagrada" (2014: 685) para los espańoles. Lo que pareciera condicionar tal aseveración es precisamente el punto 
que investiga la filósofa en el artículo: su ambigüedad y su novelería. ${ }^{5}$ Zambrano podrá vislumbrar la primera de las ambigüedades del género y configurar así la siguiente pregunta: “¿Qué significa que nuestra tragedia sea una novela?” (2014: 687). La novela se convierte en un espacio en que la criatura humana se manifiesta como un ser por fin libre, independiente de los dioses y, por tanto, de su destino trágico:

La ambigüedad de la novela procede, al parecer, de que está al nivel del hombre, de que la conciencia creadora de su autor en nada sobrepasa a la conciencia que define a nuestra época, a nuestro mundo, emancipado de lo divino. Y, en consecuencia, sus conflictos, sus personajes, son humanos, perfectamente humanos [...] El horizonte se ha estrechado al humanizarse y acciones antes heroicas han venido a ser ambiguas. Pues, ¿qué es lo ambiguo, sino el resultado de una falta de anchura en el horizonte para contener ciertas acciones, ciertas criaturas?; la incapacidad de la ciencia para albergar enteras a ciertas realidades que en otro espacio más amplio y modulado serían puras, inequívocas y aun simples (2014: 688).

En esta cita, y en otros pasajes del ensayo, Zambrano observa precisamente cómo la configuración de la novela servirá para desbordar lo que ocurría en los ámbitos aparentemente estrechos del mito: los personajes de los textos novelísticos son seres humanos

${ }^{5}$ En "La novela: 'Don Quijote'. La obra de Proust", Zambrano apuntó lo siguiente: "La novelería consiste, en principio, en creerse ser algo y necesitar de los demás que lo crean; necesita el convencido de ese su ser, que los demás se convenzan con él” (2014: 1070). Es decir, la novela representa una búsqueda en que los personajes intentarán ser creídos desde su patente irrealidad. Esta idea se vincula necesariamente con la naturaleza ambigua, para Zambrano, de lo novelesco. 
plenos que se ponen al servicio de la literatura; y la novela sirve, además, para adquirir la conciencia de esa humanidad y del alejamiento de lo divino, de su participación en la suerte prefijada de los hombres. No por nada, Zambrano señaló que "la situación de Don Quijote se hace inteligible desde el cartesiano mundo de la conciencia” (2014: 691), es decir, desde la pregunta por el propio ser. La novela refleja un fenómeno parecido al que la filósofa trazó en Filosofía y poesía en 1939, libro en que ella explica los mecanismos que llevaron al hombre a convertirse en un ser violentamente separado del ambiente de su inmediata realidad gracias a las severas operaciones del pensamiento filosófico (hacia el final de su artículo de 1947, sugeriría Zambrano la llamativa posibilidad de que sea la novela el territorio en que se reconcilien, por fin, la filosofía y la poesía). La siguiente observación de Zambrano nos ayudará para mejor entender el lugar crucial que juega la novela en la situación del hombre y en la idea que podrá obtener de sí mismo: "La novela [...] muestra mejor que ningún otro producto de nuestra cultura ese conflicto entre conciencia, razón y piedad, servidumbre a lo divino, conflicto en el que va nuestra condición humana, nuestra definición" (2014: 688). La quimera de Zambrano parece asomarse ya en las páginas de este texto cuando se examina la ambigüedad con que Don Quijote se enfrenta al mundo con una percepción más bien alterada de la realidad, como consecuencia del delirio y del ensueńo: "Parece imposible el superar la perfección cervantina en la ambigüedad. ¿Acaso don Quijote estaba convencido de la realidad de su ser inventado? ¿No entrevé, en medio de su delirio no inspirado por los dioses, que los brillantes ejércitos no son sino modestos carneros y que los molinos están allí detrás de los gigantes como un artificio fotográfico podrá hoy realizar? [sic] ¿Cree en la realidad corpórea de Dulcinea? ¿No elude acaso el ver cara a cara su presencia?” (2014: 692). 
"La ambigüedad de Don Quijote" (2014: 696-701) es un texto que originalmente apareció en francés en el año de 1948 y que, después, al igual que el texto antes comentado, se sumó al libro $E s-$ paña: sueño y verdad de 1965. Por el título, se puede pensar como una suerte de continuación y también de enriquecimiento del otro artículo, si bien hay algunas ideas que en apariencia se contraponen, lo cual no es para nada extrańo si consideramos el método de escritura y de pensamiento de nuestra autora. Lo relevante para nosotros, en todo caso, es que aquí Zambrano complementó su examen del Quijote, y de la novela como género literario, por medio del uso de la quimera en sus párrafos finales; y con una visión particular de la Espańa vencedora y vencida del Siglo Xviı. Una idea que no presentó en el otro texto, y que usa para abrir este ensayo, es la noción de la novela como la decadencia del mito; y Don Quijote como figura finalmente trágica. ${ }^{6}$ Otra novedad es la consideración de Sancho Panza como juez de su señor, pero también como el espejo del caballero andante, "juego de espejos y de imágenes que en excesiva claridad llega a ofuscar y a crear la ambigüedad” (2014: 697). Nuestra visión de Don Quijote sería el resultado de mirar entonces ese engañoso juego de espejos y de quedar atrapados en él. También la ambigüedad queda representada por la locura del caballero y particularmente por su condición, por esencia, ambivalente: "desfacedor de entuertos" y creatura, a su

${ }^{6}$ En el texto en que Zambrano se dedica al estudio del Quijote y de la obra de Proust, y que pertenecen al libro El sueño creador, encontramos unas palabras que aclaran la diferencia entre el personaje trágico y el personaje novelístico: "El protagonista de tragedia es sacrificado, y por ello, sea cual sea su acción, su infierno, es siempre inocente. El protagonista de novela, si se sacrifica, lo hace él mismo. Por ello, no se tratará nunca de un verdadero sacrificio, y corre el riesgo, si de sacrificarse hace su sueño, de ser víctima del más terrible de los sacrificios; del no aceptado. Riesgo que siempre se alza frente al sacrificio, más que no requerido, no enviado" (2014: 1071). 
vez, que requiere la ayuda y de la piedad de los demás personajes del relato. En este análisis de Zambrano, el hidalgo se convierte en una herida y en un ser trágico, pero difícilmente en un ser épico ya que no saldrá del todo victorioso de su alta empresa: su proyecto para hacer revivir la antigua caballería. Sin embargo, la autora encuentra otra ambigüedad en este mismo punto: acaso Don Quijote sea el personaje que no puede vencer, pero tampoco salir del todo derrotado: se quedaría en un espacio que desbordaría los dos polos y que incluso los anularía. Después de anotar un par de ideas acerca de la visión de Unamuno en torno al Quijote, Zambrano destaca la novelería del texto áureo; y sintetiza la personalidad del Quijote proponiendo la imagen híbrida de la quimera:

Y ahí está la novela, lugar de burlas y vencimiento de los "encantos de la historia"; los ecos, los reflejos, las grutas maravillosas, el palacio de los duques y aun el caballo de Troya; la poca duradera ínsula, la jaula en que el héroe se pasea ante los ojos del mundo despertando una ambigua admiración y una compasión atónica: la procesión que se repite. Y en los ojos, en la frente del héroe, la quimera. La quimera, él mismo, ángel y león, hacia una muerte inconclusa, perenne agonía: "Que yo, Sancho, nací para vivir muriendo". Para no acabar de morir. ¿Para no morir antes de haber resucitado? (2014: 700).

Como puede bien observarse, la novela se convierte en un espacio en que la historia puede vivir su propio ensueńo y albergar componentes que provienen de la irrealidad, de la fantasía literaria, de la imaginación libresca; en la cita están resumidos algunos de los elementos más fantasiosos o maravillosos con que se puebla la novela cervantina y que teóricamente distorsionan el realismo supuestamente imperante del texto. Es Don Quijote, según leemos, el personaje que se pasea en una jaula provocando burla y -al mis- 
mo tiempo- veneración. Es también el personaje que vive y muere como hombre y como caballero andante. Zambrano incluso llega a presentarlo como un ser formado por dos esencias, como un ser quimérico: ángel y león. La ambigüedad se reconoce, por su parte, en el personaje de Dulcinea por medio, también, de la quimera: “¿No estará en Dulcinea el secreto? ¿No está acaso encantada también? ¿Separada, absoluta, reducida a esencia, a idea, llevada al mundo de la quimera, ella, que es viviente realidad? ¿Qué le sucedió en verdad a Don Quijote con Dulcinea? ¿Qué le sucedió a Cervantes?” (2014: 701). En Dulcinea, se va a manifestar la quimera por su condición de mujer real, de mujer imaginada y de mujer, finalmente, encantada debido al engaño practicado por Sancho en la segunda parte del libro. El ensayo analizado termina con un párrafo en que el concepto de la quimera se convierte todavía en una concepción más compleja y en que el lector podrá reconocer nuevamente el lugar de la novela como un territorio en que podrán convivir las ambigüedades de la historia, del sueño, de la ficción, de lo verdadero y de la realidad. Además de que-elemento que no se había percibido anteriormente en el texto de Zambrano- la quimera adquiere una carga adicional como símbolo de un momento en la vida de Espańa:

La figura de Don Quijote, portadora de ancestral sueño de la libertad encadenada, manifiesta el conflicto de ser hombre en la historia, contra ella, a través de ella y un más allá de ella. Y aparece revelada por su autor en el momento en que la historia de España cae sobre el hombre espańol, cansado ya de ella, en que por no reconocerse en ella, se va a retirar un momento después, estigmatizado, entrando en su derrota para limpiarse y purgar tanta victoria. Es signo y clave de que, sea cual fuere esta historia, no hemos tenido vocación de vencer. Pero esta historia no se acaba. 
Reaparece una y otra vez la quimera -salvar al mundo de su encanto-, mientras Dulcinea sola y blanca se consume (2014: 701). ${ }^{7}$

\section{La quimera y Misericordia}

El primer texto que Zambrano dedicó al estudio de la novela de Pérez Galdós apareció en la revista Hora de España en 1938. Si bien la quimera no se incluye todavía en dicho texto, me parece que será importante señalar por lo menos un par de ideas que después se proyectarán en el ensayo que centralmente analizaremos del libro La España de Galdós (1960). Lo primero que habría que destacar de este artículo es el hecho de que la autora nos proponga nuevamente las vinculaciones entre la ficción y la historia: su dialéctica.

En las primeras páginas del ensayo de 1938, la filósofa argumentó que en Misericordia, volumen perteneciente al periodo de escritura de las afamadas novelas contemporáneas, se dejan entrever elementos en apariencia ocultos, elementos provenientes de épocas previas en la historia de la nación, lo cual nos remite, según lo creo, a la noción de lo intrahistórico: "Es la presencia del ayer histórico en un presente sin relieve. Su nostalgia y su deformada imagen en el espejo de una actualidad desmemoriada" (2014: 570). Es decir, se trata de una novela en que resurge el pasado no del todo asimilado por el pueblo y por la sociedad de España. La otra cuestión que debería ser rescatada en el contexto de esta investigación, por la importancia que tendrá posteriormente en el

${ }^{7}$ En España, sueño y verdad, también se incluye "Lo que sucedió a Cervantes: Dulcinea”. En este ensayo, no aparece la quimera. De forma inversa, hablará en él la filósofa de la amada de Don Quijote como "un hecho irreductible", como "una realidad sin ese hueco del que todo lo real parece emerger" (2014: 704), en apariencia, sin ambigüedades. En este texto, Zambrano explica la escritura y el origen del Quijote, por cierto, como producto de una revelación experimentada por el autor de la novela. 
análisis de la quimera, es la tipología que Zambrano realiza con los personajes de acuerdo con su capacidad o con su incapacidad para desenvolverse en la vida, para entender y negociar su irrenunciable vínculo con la realidad y con la tradición, con la avidez que significa vivir y resguardar una esperanza. Cada uno de los personajes vivirá a su modo el mismo problema y con diversos resultados. Zambrano incluso percibió, de forma general, que "el mundo de Misericordia es ya una lucha entre la prodigalidad popular y la rencorosa inhibición, el miedo de la vida” (2014: 578). Así veremos cómo enfrentan las desgracias, de forma variopinta, seres tan diversos como lo son Frasquito Ponce (personaje cercano al Quijote, según Zambrano), Doña Paca y su hija (mujeres prácticamente afantasmadas), Mordejai (absolutamente sumido en la fantasía de lo mágico), y Benigna de Casio, personaje que resuelve mejor que ningún otro el conflicto planteado y que, por tanto, no vive con la dificultad de pactar entre los sueńos y la realidad, entre la vida y la fantasía, entre el pasado histórico y el momento en que le toca vivir y sobrevivir:

[...] es en sí misma [Nina] -agua pura y viva brotando entre escombros-, y porque es ella la clave de todo ese mundo complicado. Agua y roca a la vez. Ella es lo más vivo que hay; el presente, la actualidad de la vida libre de residuo alguno, libre de toda traba. Presente que, al renacer en cada instante, es porvenir descendiendo hacia la realidad desde el infinito horizonte de lo posible; la verificación más fiel de la esperanza (2014: 582).

Estos rasgos serán los que den al personaje de Nina, en la lectura de María Zambrano, un lugar tan especial si se piensa en la novelería de todos los demás. De hecho, en el otro ensayo largo que dedicó a la cuestión, la filósofa incluso interroga si se trata o no de un personaje de novela, por la manera tan particular con que 
se comporta y con que enfrenta los dilemas recurrentes, dilemas suyos y de los demás personajes que ella cuida, protege y guía, por la forma en que ha quedado totalmente libre de la "pasividad extrema” (2014: 526) en que existen los otros. Incluso, Zambrano afirma que Nina desnoveliza, por su contacto estrecho y por su conducta, a todos los personajes que la rodean; y duda del hecho de que Nina posea su propia quimera: “ ¿Nina es de veras un personaje novelesco? ¿Tenía su quimera? ¿La figura de su vida ofrece esa ambigüedad polivalente de lo quimérico?” (2014: 545). Para nuestra autora, incluso la contextura de Misericordia y el comportamiento de su protagonista redibujan entonces el concepto de novela que podríamos trazar, por ejemplo, tras la lectura del Quijote:

No hay novelería alguna desde el principio en la novela Misericordia, que nos parece constituir en centro de la inmensa obra galdosiana. ¿Es acaso Nina, la protagonista de Misericordia, un personaje de novela? Pues que Nina empieza su peregrinar donde Don Quijote lo acaba, mas sin reconocerse, como si nunca se hubiera sońado a sí misma. Su historia, como se verá, es la historia de alguien que se adentra en la verdad y en la vida habiendo estado desde el principio tan en ella. Si alguna novelería tuvo se le fue sin dejar rastro, y no entró en su verdadera historia. Sirve ella así también para hacer visible la novelería de los demás personajes que la rodean y, por irradiación, la de todos los personajes del mundo de Galdós. Y siendo ella el centro de la novela, no la engendra, más bien la deshace o, al menos, cuanto mira: personajes y personas, lugares, paisajes, el polvo de los caminos, la luz del alba, el amor de una simple mujer (2014: 531).

Desde el prólogo de la primera edición del La España de Galdós, la filósofa recurre a la imagen de este animal imaginario para enmarcar la discusión y delinear su interpretación del personaje 
de Nina. En dicho prólogo, se advierte que Nina no lleva máscara alguna y que es "invisible casi a fuerza de tan blanca, tendiéndonos en sus manos apenas nada, un hilo se diría: un hilo liso, como agua que ha ido sacando de la enmarañada madeja que se le dio a devanar. El hilo quizás de la quimera que se sobrepone a la vida, el hilo de la vida que prosigue, el que habría que sacar de toda la historia y de toda vida, sin romperlo ni mancharlo" (2014: 521). A lo largo de las páginas del libro, Zambrano se ocupa, precisamente, de investigar cómo los diversos estratos de la realidad y de la irrealidad, de la historia, del sueńo y de la vida, se van sobreponiendo y luchando para intentar imponerse, tarea que sería responsabilidad centralmente de Benigna, su conciliación o reconciliación en los territorios del "infierno de la novela" o de "la quimérica vida novelesca” (2014: 521). Es Benigna, como lo acabamos de observar en la cita, la encargada de guardar y de otorgarnos a nosotros, los lectores, el "hilo de la quimera", imagen que nos remite al hilo liberador de Ariadna; por tanto, a la salida del laberinto o del ínfero.

Uno de los asuntos que la filósofa desarrolló con amplitud en el texto de este segundo ensayo acerca de Misericordia es precisamente la situación del hombre en el laberinto de lo histórico, la situación del hombre atrapado en las circunstancias que lo filian con una época determinada y con unas circunstancias no escogidas por él, "la condenación de la historia sobre la vida" (2014: 528). Zambrano percibe, en este contexto, la historia incluso como una desconocida deidad de la que el hombre pocas veces logra escapar; esto resulta particularmente cierto, según ella, en el caso de España por las especificidades de su formación y de su devenir histórico. ${ }^{8}$

${ }^{8}$ La historia también quedará representada en este ensayo por medio de una imagen animalesca, que no nos remitirá al mundo de lo fantástico, pero sí a lo simbólico: "Esa sierpe sin fin del tiempo histórico, de la historia y las historias, que con sus anillos rodea al ser humano y aun lo fascina y le hace perder el sentido" (2014: 526). Y la figura de la paloma, de acuerdo con Zambrano, 
Para Zambrano, Galdós coloca a todos sus personajes en dicha encrucijada. Lo que podemos atestiguar como lectores es la manera en que cada una de sus criaturas logra escapar o ser sacrificada por la historia y, también, si escoge vivir la vida (como en el singular caso de Nina) o si prefiere la búsqueda o la invención de otra realidad paralela (como ocurriría con Don Quijote). Los personajes de una novela, según la filósofa, tienden a sacrificar su vida reduciéndola a lo que ella denomina como el esquema. Benigna de Casio escaparía precisamente de ese sacrificio y del esquema, lo mismo que Don Quijote de la Mancha, pero con otros mecanismos y alcances diversos. En otra tipología complementaria, Zambrano propone que los personajes tienen una relación conflictiva o no con la realidad: buscan pertenecer a ella o superarla o bien, incluso, devorarla; muchas veces terminan siendo aplastados por lo real, por lo innegociable de la realidad que irremediablemente se les impone (es el prototípico caso del ama de Nina y de su hija, particularmente en las últimas páginas de Misericordia). El caso de Don Quijote es especial, pues como sabemos vive en un mundo trastornado por su experiencia como lector de novelas; no puede imponer a los otros su concepción del mundo por más que lo intente en cada nueva aventura, además de que ha de necesitar la misericordia y la piedad de los otros. Zambrano representa este conflicto en toda su complejidad -desde un punto de vista simbólico- con la quimera. Interesantemente, apunta nuestra filósofa que Don Quijote, al recuperar la cordura hacia el final del libro cervantino y convertirse en Alonso Quijano el Bueno, termina por renunciar a esa combinación entre los sueños y la realidad: "Su quimera cedió el paso a la unidad triunfante” (2014: 545). La uni-

servirá para representar la personalidad de Benigna, por tratarse de un ave que constantemente cambia de lugar, así como Nina iba y venía por los caminos de Madrid con la intención de ayudar a aquellos que la rodeaban. 
dad es la conciencia ganada, digamos, de su verdadero ser. En este contexto, ella propone la criatura mixta y fantástica de la quimera como símbolo del proceso que resultaría de entremezclar piezas que vienen de ámbitos en oposición:

En el lugar de la vida, donde vida y realidad se amalgaman, y ciegos los seres se confunden no sabiendo si han de vivir o si han de ser solamente reales, teniendo de la vida la insatisfacción ante la realidad que se torna en exasperación cuando la ven sobre sí después de haberla perseguido tanto. Pues parece propio de la humana condición apetecer cobrar la realidad $y$, una vez sentida, rechazarla como si se hubiese caído en una trampa o como si se hubiese anexionado algo que no puede transformar en vida; algo como una figura de sueño que se hubiese quedado adherida, sin volverse a su reino, alimentándose de forma extraña: prefiguración de la quimera (2014: 539).

En la cita previa se describe una situación en que no logran los personajes del todo despegarse del sueño: es entonces cuando la quimera surge como inmejorable símbolo de su circunstancia: se revela y se erige luego como emblema de lo ambiguo. Zambrano insiste en este tipo de observaciones: la posibilidad de definir la esencia de los personajes por medio de esa ambigüedad, de tal modo que podrá apuntar que "lo novelesco de un personaje reside en vivir dentro de un sueño, agarrándose a él con un esfuerzo que casi lo despierta" (2014: 545).

En un momento fundamental de este mismo ensayo, Zambrano reflexionó acerca de la naturaleza de la quimera. Su opinión acerca de la forma en que la quimera está constituida resulta, según creo, bastante original, pues no ha de obedecer la tradición literaria. Pensemos en el epígrafe con que se enmarcó este trabajo de investigación y en que se recupera el mito tradicional del animal 
según las fuentes clásicas. De acuerdo con lo establecido en el $M a-$ nual de zoología fantástica, según la tradición milenaria, la quimera sería un animal dividido en tres partes completamente diferenciadas: la parte primera habría correspondido a la fisonomía del león, la intermedia a una cabra y la sección final a una serpiente. La quimera sería entonces, por supuesto, una imposibilidad lógica y, desde luego, también biológica y aun fisiológica. Para Zambrano, sería la materialización plena y simbólica de lo ambiguo; más que tratarse de la reunión de partes que difícilmente podrían reunirse en un ser nuevo, sería la imagen o el emblema de la ambigüedad más allá de la irrealizable mezcla de lo que, por principio de cuentas, no podría reunirse ni resolverse en una sola entidad por motivos, si se quiere, anatómicos. En otros términos, la quimera no es tampoco lo imposible o lo inexistente; es algo más:

La quimera es una figura híbrida -pluralmente-, como para señalar que su hibridismo no proviene de la imposible unión de dos seres, sino que se trata de algo ambiguo esencialmente. Y, ¿qué ambigüedad más esencial que aquella surgida entre la realidad y el sueño, entre el andar en sueńos y el abrirse y despertar con decisión de permanecer en él? Ambigüedad llevada al extremo, porque siempre sucede; vivir humanamente es eso: ese perenne, nunca resuelto, salir del sueño a la realidad; ese movimiento pendular como de alguien atraído por dos centros de gravedad -dos polosque se da aun en sueños (2014: 545).

Si en los textos en que estudió el Quijote puso su atención en la ambigüedad de la novela cervantina, y del género literario a que ésta pertenece, en las páginas de La España de Galdós Zambrano regresa al concepto, y desde luego a la imagen de la quimera, pero proponiendo que el espacio novelístico sería el de la ambigua unión entre lo real y lo soñado: una manera, acaso, del ensueño. 
La quimera, como lo veremos de inmediato, ha de servir para que los personajes enfrenten la desazón de sus vidas, el penoso estado en que se encuentran: el diálogo será el mecanismo que servirá para invocar la quimera. Recordemos la importancia que tiene el diálogo en las novelas y en la configuración de los personajes literarios. Como bien lo vio Mijaíl Bajtin, "el autor concibe su héroe como un discurso" (152). Y ese discurso surge con mayor brillo, precisamente, en las circunstancias dialógicas.

Algunas de las páginas más deslumbrantes de Misericordia de Pérez Galdós son aquellas en que Nina habla con su señora, dońa Paca. Sobre todo, por lo que el lector conoce y reconoce y dońa Paca ignora o quiere ignorar: el increíble hecho de que su criada sea la responsable de mantenerla. En el comienzo del libro, encontramos a Nina como mendiga apostada en la puerta de una iglesia de Madrid; con el dinero conseguido de este modo, engańará a su ama, una mujer que por las malas decisiones económicas ha terminado por dejar de ser doña Francisca y convertirse llanamente en doña Paca. Uno de los mayores logros de Galdós en el entramado del texto novelístico son aquellos episodios en que estas dos mujeres dialogan. A su vez, podríamos señalar que uno de los instantes inolvidables de La España de Galdós ocurre cuando Zambrano analiza esos diálogos y encuentra la razón profunda de los mismos, su funcionalidad. Como bien lo saben los lectores de Misericordia, Nina se verá obligada a mentir: nunca dice con toda claridad de dónde saca el dinero e inventará al inexistente personaje del padre Romualdo, su imaginado e inventado patrón (que luego maravillosamente ha de materializarse). Zambrano justifica las mentiras de Nina bajo la consideración de que doña Paca, absolutamente derrotada, se encontraba cerca del abismo. Es más, nos dirá Zambrano que ni siquiera "tenía ya ni quimera la señora, a fuerza de estar vencida. La vida no la dejaba. Débilmente, bajo la pesadumbre del peso de la vida, y hundiéndose en ella misma, en el vértigo de 
su irrealidad, se agarraba a su pasada quimera de otros días, cuando andaba arrastrada por el vértigo, al borde de su abismo" (2014: 548). De tal modo que no le queda de otra a Nina que invocar a la quimera, una "modesta quimera de porvenir" (2014: 549). La quimera aquí se vincula con esa capacidad fantasiosa que permite al ser humano, en este caso, a doña Paca, vislumbrar con avidez una realidad distinta de la que se enfrenta, pues de otro modo la única salida sería la desesperación y acaso la muerte. Zambrano nos advierte que la verdad puede volverse inmanejable; pues hay quienes -como ocurre con un sinfín de personajes galdosianos- tendrán que vivir "sumiéndose en la irrealidad, fascinándose con la quimera” (2014: 552). Ahora bien, la proyección del personaje que acude a su quimera, como lo denota la siguiente cita, es hacia el pasado, hacia el territorio de las posibilidades fracasadas con la intención de enfrentar así la angustia inmediata del momento presente. De este modo, se va intercambiando la avidez por la esperanza, en un juego de opciones ambiguas y, por tanto, quiméricas:

La criatura humana presidida por una quimera está encadenada al pasado, al de la vida y aun al pasado de su propia vida. Incapaz de liberarse no sólo de lo que fue, sino de lo que pudo haber sido, y más todavía, de lo que quedó en esbozo, en intento, de la posibilidad apenas gustada o emprendida. La quimera, más que enseña del futuro, es, como toda esclavitud, marca del pasado, de un pasado que no llegó ni podía cobrar forma: la ambigua dote recibida por un sujeto viviente que ha de ir con ella y contra ella, reduciéndose a su unidad, a su verdad, viviendo.

Y así, a medida que se libra de la quimera, la esperanza vence a la inconmensurable avidez. O quizás suceda a la inversa: que por ir ganando la esperanza a la avidez, vaya entregando sus monstruos, su prehistoria. 
¿Existirá una relación entre el hallarse bajo la fascinación de la quimera y el incesante justificarse? Ciertamente, la quimera no exige justificación, sino entrega o seguimiento o menos: que la persona se le dé en pasto, pues que la quimera, "ente" sin sustancia ni vida propia, los toma de la otra persona ante la cual se alza, cortándole el paso. Y la persona ha de irle entregando instante a instante su hacienda, aquello de que dispone para ir dibujando esa figura en el tiempo. La quimera corta el tiempo, se interpone en su pasar, deja en suspenso a la persona que por ella se convierte en personaje (2014: 555).

En las líneas aquí citadas, Zambrano se pregunta si los personajes se justificarán en presencia de la quimera. Más allá de las dificultades de comprensión que puede acarrear este pasaje, es de suponerse que el planteamiento tiene que ver con un acto de sinceridad de las criaturas literarias frente a su ensueño, es decir, frente a la ambigua situación en que se encuentran. En su análisis, nuestra filósofa sugiere que una de las diferencias principales entre Don Quijote y Benigna sería precisamente esta: la necesidad que tendrá el caballero andante de justificarse; en cambio Nina, por la absoluta vitalidad y honestidad con que vive, no necesitará explicación ni justificación frente al mundo. Sencillamente se ocupará de recorrer los caminos matritenses buscando aquello que resulta indispensable obtener para no dejar de vivir. Nina se mueve por los infiernos de la novela, pero con la certidumbre y la seguridad con que nunca podrán caminar los demás personajes tan llenos de novelería. 


\section{Conclusiones}

\section{La blanca quimera parece que sueña}

Antonio Machado, "Fantasía de UNA NOTA DE ABRIL"

En las páginas previas, hemos revisado ensayos importantes de Zambrano que tienen por lo menos tres elementos en común: 1) son ejercicios de crítica literaria; 2) en ellos se despliega la razón poética como instrumento para la lectura y el comentario de las novelas, y 3) la presencia de la quimera.

He dicho que son ensayos de crítica literaria por las particularidades evidentes con que los artículos están escritos y, sobre todo, por la búsqueda de la construcción del conocimiento por medio de la consideración minuciosa de los textos; sin embargo, el segundo elemento destacado, el uso de la razón poética, puede servirnos para entender del todo la forma dinámica con que se arma y se incita ese conocimiento singular. Como lo determinó Chantal Maillard, "lo que la razón-poética pretende ser como método es un modelo para que cada persona pueda formular su propia teoría, su propio universo metafórico, bien entendido que toda formulación se realiza a través de un proceso y que, en este caso, lo esencial es el proceso" (168). Es de llamar la atención que los artículos que nuestra filósofa escribió a lo largo de distintas épocas conserven, sin embargo, algunas ideas esenciales, invariables y recurrentes; y que constituyan en gran medida el proceso del cual nos habla Maillard en la cita.

Sin duda, podremos destacar la ambigüedad como elemento esencial de la novela en la mirada de Zambrano. La autora se sintió vivamente intrigada por las características del género, pero también por sus orígenes. En un texto recobrado por Aurora. Papeles 
del Seminario María Zambrano, la filósofa brevemente trazó el origen de la novela; como Marcelino Menéndez Pelayo, encuentra que "la novela occidental es hija, como se sabe, de las fábulas y cuentos del Oriente: de la India principalmente, llegadas a través de esos grandes mediadores entre Oriente y Occidente que fueron árabes” (2001: 147). Ahora bien, su concepción de lo novelístico es profundamente personal y rebasará la mirada histórica y filológica del fenómeno; algo que fuertemente prueba su aportación al estudio de la novela y su coherencia es el hecho de que haya reutilizado algunas de las mismas ideas e instrumentos de análisis para el examen de obras tan lejanas desde un punto de vista temporal y también estilístico: el libro más famoso de Cervantes y una obra "central", según lo remarca Zambrano, en la producción de Galdós como lo sería Misericordia. Me refiero, desde luego, a la quimera como recurso para la exégesis y la investigación del texto literario.

Hemos reconocido que la quimera es, en el contexto de los ensayos de nuestra filósofa, una alegoría, es decir, una consecuencia directa y simbólica del pensamiento que se nutre de lo metafórico; obligadamente rebasa lo puramente conceptual, puesto que, para la filósofa, "la metáfora es una forma de relación que va más allá y es más íntima, más sensorial también, que la establecida por los conceptos y sus respectivas relaciones" (1989: 120). En el estudio de los textos literarios, la metáfora se convirtió en un recurso de primer orden para la escritora como bien lo ha observado Greta Rivara Kamaji:

[...] el uso de la metáfora a través de la razón-poética puede ser, para María Zambrano, el lenguaje constituyente de una manera de conocer, de un modo, de una actitud de conocimiento, que partiendo de un ímpetu filosófico puede también penetrar en las más profundas problemáticas, volteando su mirada hacia otros órdenes del saber, hacia otros dominios del conocimiento. De este 
modo, María Zambrano intenta acercarse, a través del lenguaje de la razón-poética, al arte, y fundamentalmente a la literatura (103).

La quimera se transforma, como lo podremos derivar de estas palabras, en un mecanismo de acercamiento a los textos literarios, en un camino que queda fundamentado, además, por la razón poética que actúa. No es de extrańar que Zambrano recurra a lo metafórico para poder explicar asuntos centrales, como lo sería el complejo funcionamiento de los textos cervantinos y galdosianos. Recuérdese que, según su perspectiva, "la metáfora es una definición que roza con lo inefable, única forma en que ciertas realidades pueden hacerse visibles a los torpes ojos humanos" (2005: 51).

Así como la quimera es un animal fantástico, que puede combinar en su ser animales de distinta procedencia, Zambrano la utiliza como símbolo de diversos matices y fenómenos que caracterizarían el discurso novelístico y la conducta de los personajes en las obras literarias: es un símbolo inestable. Nuestra filósofa descreyó del hecho de que las metáforas tuvieran una obligada interpretación unívoca; al contrario, creyó que las metáforas podían albergar inagotables sentidos, de tal modo que la quimera podría ser, por ejemplo, el paso entre la vigilia y el sueńo; o bien, las imágenes de un pasado dichoso e irremediablemente perdido; e incluso contener algunos significados que terminan por escaparse de la comprensión inmediata del lector potencial de sus ensayos. No debe resultarnos extrańo que, por un lado, la quimera simbolice un conjunto de elementos y recurrencias y que, por el otro, no se mantenga en todos los casos como una representación fija o puramente conceptual de algo específico. Ocurre con la quimera de María Zambrano algo parecido a lo que Antonio Machado escribió al imaginar las ideas del muy sabio poeta Abel Martín: "La lógica real no acepta supuestos, conceptos inmutables, sino realidades vivas, inmóviles pero en perpetuo cambio. Los conceptos o formas captoras de lo real no 
pueden ser rígidos, si han de adaptarse a la constante mutabilidad de lo real" (339).

\section{Bibliografía}

Abellán, José Luis, 1998, "María Zambrano: el itinerario de la 'razón poética", en El exilio filosófico en América. Los transterrados de 1939, Fondo de Cultura Económica, México, pp. 257-284.

Astey, Gabriel, 2010, Figuras de la vida anímica. El corazón según María Zambrano, Universidad Autónoma Metropolitana, México.

Bajtin, Mijaíl, 2012, Problemas de la poética de Dostoievski, Tatiana Bubnova (trad.), Tatiana Bubnova y Jorge Alcázar (intr. y ed.), Fondo de Cultura Económica, México.

Borges, Jorge Luis y Margarita Guerrero, 1957, Manual de zoología fantástica, Fondo de Cultura Económica, México.

Bundgård, Ana, 2018, "La ambigüedad de un género en movimiento", Aurora. Papeles del Seminario María Zambrano, núm. 19, pp. 6-16.

Johnson, Roberta, 1996, “María Zambrano's Theory of Literature as Knowledge and Contingency", Hispania, vol. 2, núm. 79, pp. 215-221.

Machado, Antonio, 2001, Poesías completas, Manuel Alvar (ed.), Austral, Barcelona.

Maillard, Chantal, 1992, La creación por la metáfora. Introducción a la razón-poética, Anthropos, Barcelona.

Ramírez, Goretti, 2004, María Zambrano, critica literaria, Devenir, Madrid. 
Rivara Kamaji, Greta, 2002, "La función de la metáfora en la razón poética de María Zambrano", Acta Poética, vol. 23, núms. 1-2, pp. 93-108.

Warren, Austin y René Wellek, 1966, Teoría literaria, Dámaso Alonso (pról.), José María Gimeno (trad.), Gredos, Madrid.

Zambrano, María, 1989, Notas de un método, Mondadori, Madrid. ,2001, "Los orígenes de la novela", Aurora. Papeles del Seminario María Zambrano, núm. 3, pp. 147-148. , 2005, Hacia un saber sobre el alma, Losada, Buenos Aires. , 2014, Obras completas III. Libros (1955-1973). El hombre y lo divino. Persona y democracia. La España de Galdós. España, sueño y verdad. Los sueños y el tiempo. El sueño creador. La tumba de Antígona, José Moreno (ed.), Galaxia-Gutenberg, Barcelona. , 2015, Obras completas I. Libros (1930-1939). Horizontes del liberalismo. Los intelectuales en el drama de España. Pensamiento y poesía en la vida española. Filosofía y poesía, Jesús Moreno Sanz (ed.), Galaxia-Gutenberg, Barcelona. 